\title{
An Investigation into How Grade 5 Teachers Teach Natural Science Concepts in Three Western Cape Primary Schools
}

\author{
Beata Set ${ }^{1, *}$, Joanne Hadman ${ }^{2} \&$ Daniel Opotamutale Ashipala ${ }^{2}$ \\ ${ }^{1}$ Department of Humanities, School of Education, Faculty of Education, University of Cape Town, South Africa \\ ${ }^{2}$ Department of General Nursing Science, School of Nursing, University of Namibia, Keetmanshoop (UNAM), \\ Namibia \\ *Correspondence: Faculty of Education, University of Namibia (UNAM), PO Box 2717, Keetmanshoop, Namibia. \\ Tel: 264-63-220-2018. E-mail: bset@unam.na
}

$\begin{array}{ll}\text { Received: November 18, } 2016 & \text { Accepted: Decmeber 15, } 2016 \quad \text { Online Published: January 17, } 2017 \\ \text { doi:10.5430/wje.v7n1p33 } & \text { URL: http://dx.doi.org/10.5430/wje.v7n1p33 }\end{array}$

\begin{abstract}
Purpose: The rationale behind this study was to investigate how three Grade 5 Natural Sciences teachers in three Western Cape primary schools teach science concepts so as to enable the researcher to gain a deeper understanding and more insightful perception of the ways in which the pedagogical practices of South African primary school teachers influence conceptual learning in the science classroom.
\end{abstract}

Methodology: The sample comprised three teachers in a specific metropole district in the Western Cape. A qualitative approach was employed to ensure the collection of rich data.

Results: The findings indicated that teachers tend to ignore learners' misconceptions in class, that they rely heavily on everyday empirical examples, that they fail to link these empirical examples to scientific concepts and that they devote little talk time to explaining scientific concepts.

Recommendations: Based on its findings the study proposed a model of classroom practice that focuses on promoting effective science learning with the aim of developing and transforming the everyday, familiar knowledge of learners into new understandings of school-based scientific concepts and processes.

Conclusion: The data from the study suggested that there may almost certainly be serious shortcomings in the instructional practices of teachers and that such shortcomings are not confined to the three schools in the sample but are to be found in township primary schools in general. In addition, these shortcomings may require immediate intervention on the part of senior curriculum specialists as well as teacher training higher education institutions (HEIs).

Keywords: mediation; misconception; scientific concepts; scientific knowledge; everyday concepts

\section{Introduction}

South Africa has recently introduced a new Curriculum and Assessment Policy Statement (CAPS) which was designed, among other things, to encourage the active involvement of learners in the learning of conceptually demanding subject matter across the various grades and learning areas. This curriculum emphasises the need for educators to adhere to the rigid standards or frameworks of both the content and the processes to be taught to each grade and phase. Unfortunately, the sheer volume of this content often results in teachers having to rush in order to cover the material and without engaging in in-depth teaching. Fleisch (2008) and Taylor (2008) have reported that quality science teaching may make a significant difference to the learning process, arguing that the poor performance of students in science, particularly in South Africa, may be attributed to the science teachers' own lack of scientific knowledge, together with their beliefs about the way in which science should be taught.

In his account of teaching methods in South African primary schools, Fleisch (2008) reports that the misinterpretation of the curriculum by teachers exacerbates the poor academic performance of the majority of learners. He describes how, instead of lessons in which teachers skilfully mediate and learners actively construct knowledge, the prevalent misinterpretation by teachers of the notion of the teacher as a mediator of learning and 
children constructing their own knowledge leads to undirected lessons "in which intellectual order, focus and discipline" are absent, and in which teachers provide little to no content of the subject in question (Fleisch, 2008, p. 136). He claims that, in many cases, the teachers' knowledge of how students learn concepts at school is limited and, as a result, teachers are not able to devise appropriate and effective teaching strategies. In addition, the majority of teachers fail to convey to the children the basic methods and procedures for learning (Fleisch, 2008).

Several aspects of the current educational context in South Africa together make a powerful case for finding sustained and innovative ways of improving science teaching in primary schools. The majority of primary schools in South Africa are reported to be struggling to offer high quality instruction in science and mathematics to the majority of school learners. This is a particular problem in rural and township schools (Hardman, 2005; Fleish, 2008).

Poor performance in science has been reported in national, regional and international tests. The concern about science education and science standards has been exacerbated by worries that South Africa was ranked extremely low in the 1993, 1998/9, 2003 and 2007 Trends in International Mathematics and Science Study (TIMMS), with the country coming last behind other African countries that spend far less of their budgets on education than does South Africa. In addition, in 2005, the National Learner Assessment Programme revealed the Grade 6 learners' performance in science was extremely disappointing (DoE, 2005). It has also been reported that local primary school learners are not able to do mathematics or execute tasks at the appropriate grade levels or at the minimum expected competence levels Fleisch; Schollar, 2008). The 2004 Western Cape Grade 6 numeracy tests found that 15\% only of learners were performing at the appropriate grade level, with a disappointing $40 \%$ operating at the Grade 3 level (Fleisch, 2008). This has led some scholars to conclude that $80 \%$ of South African learners are below the minimum expected standard for their grades (Schollar, 2008). It would appear that a matter of particular contention is the reasons why so many schools continue to fail in their quest to improve the teaching and learning of science and mathematics.

\subsection{Problem Statement}

Despite the efforts of the Department of Education to employ qualified teachers and provide them with ongoing professional development, there is evidence that the instructional practices of teachers have also been found to exacerbate poor learner performance rather than their instructional practices serving to support learners as regards quality learning in science (Fleisch, 2008; Muthivhi \& Bloom, 2008). The researcher is not aware of any studies which have been conducted in South African township primary schools to investigate the ways in which the instructional talk and practices of South African primary school teachers hinder or influence the learners' conceptual learning and understanding in the science classroom.

\subsection{Research Questions}

The following research question was posed: How do Grade 5 teachers teach natural science concepts to primary school learners?

\subsection{Research Purpose}

The aim of the study was to explore and observe how Natural Sciences teachers teach science concepts in Grade 5, and the extent to which the teachers' perceptions and beliefs about how science should be taught influence their teaching practices.

\subsection{Research Objectives}

The objectives of this study included the following:

- To explore the way science concepts are taught to primary school learners

- To observe how the teachers in the study used everyday concepts to explain or provide familiar examples in their teaching of science concepts

- To identify teachers' beliefs, and perceptions about the way the Natural Science should be taught to primary school learners.

\subsection{Significance of the Study}

It is hoped that the outcomes of this study will be of great value to the research community, that they will serve to inform the future professional learning of science teachers and will also lead to a better understanding of the extent to which the instructional practices of teachers affect learners' conceptual development, thus leading to the enhancement of learners' performance in science. In addition, the data generated from this research may be used in teacher training institutions to train teachers on instructional practices that have an impact on learners' conceptual development. 


\section{Study Design and Methods}

In order to accomplish the study objectives outlined above, the study used a qualitative approach in order to generate rich data. Based on the nature of the exploratory main research question formulated for the purposes of the study, the research study was situated within an interpretive paradigm, with the qualitative case study as the focal research method used in the study. The qualitative case study methodology was chosen because it provides the researcher with the tools required to interrogate complex issues within a particular and specific context, such as studying individual or specific historical events, or, in the case of this study, teaching practices, in order to understand best practice cases and those that are otherwise, holistically (Baxter \& Jack, 2008).

\subsection{Sample}

The participants targeted for the purposes of the study were the three Grade 5, Natural Science teachers.

\subsection{Sampling and Sample Size}

All the participants were selected using a "purposeful sampling" approach in terms of which "researchers intentionally selected participants to understand the central phenomenon" (Creswell, 2005, p. 204). In terms of this approach samples are selected on the basis of certain criteria in respect of particular features that allow the exhaustive exploration and understanding of a central phenomenon which the researcher intends studying (Ritchie et al., 2003).

\subsection{Data Collection Procedure (Instruments and Methods)}

The study used interviews and observations as the methods of investigation and these contributed immensely both to the richness of the data and to the researcher's interpretation of the data. In addition, each of the data sources used in this study contributed to the triangulation of data necessary to ensure the trustworthiness of the study as each captured a different perspective of the research topic.

\subsection{Data Analysis}

All of the interviews conducted with the teachers were transcribed, collated and analysed for commonalities and differences. In addition, as with the transcribed lessons which had been observed, the data contained in the transcriptions was coded into broad themes which were related to the sub-research questions which, in turn, were linked to the main research question. These themes were then entered into a matrix to enable comparisons. Six broad categories were identified, namely, concepts, misconceptions, feedback, management talk, questions and learners' responses.

\subsection{Trustworthiness}

Triangulation, member checks, feedback to the participants and the checking of information were integral to the research process to ensure the trustworthiness of the study. Trustworthiness was also achieved by asking the participants to read the transcripts of their interviews to ensure that what had been transcribed was what they had intended to convey. In addition, the researcher watching the video-taped lessons with the teacher concerned to facilitate discussions on the teacher's teaching strategies as well as to obtain clarity, where necessary, on any misinterpretations to also to clarify aspects of the data collection and data analysis or to make amendments.

\subsection{Ethical Consideration}

The proposal for the study was submitted to the University of Cape Town's Ethical Committee for ethical clearance. In addition, a letter was sent to the Western Cape Education Department and to the principals of each of the schools selected for the study, requesting permission to conduct the research study at the schools in question. Permission to do so was granted. The purpose of the study was clearly explained to the participants, who were requested to give their consent to their lessons being observed and recorded. Before conducting the classroom observations and interviews, the researcher assured the participants that all the data collected during the interviews and observations would be kept secure and treated as confidential.

\section{Results}

The results presented were obtained from the classroom observation and interviews which were conducted with the aim of exploring the respondents' teaching practices in relation to Natural Sciences concepts.

Table 1 below presents all the concept and sub-concepts codes together with a definition of each and examples extracted from the data. The table also shows the percentages that explain the manner of how concepts that were being taught by individual teachers. 
Table 1. Summary of the Observation Analysis

\begin{tabular}{|c|c|c|c|c|c|}
\hline \multirow[t]{2}{*}{ Concept } & \multirow[t]{2}{*}{ Codes } & \multirow[t]{2}{*}{ Definition of Codes } & \multirow{2}{*}{$\begin{array}{l}\text { Teacher } 1 \\
\text { Observed } \\
\%\end{array}$} & \multirow{2}{*}{$\begin{array}{l}\text { Teacher } 2 \\
\text { Observed } \\
\%\end{array}$} & \multirow{2}{*}{$\begin{array}{l}\text { Teacher } 3 \\
\text { Observed } \\
\%\end{array}$} \\
\hline & & & & & \\
\hline \multirow[t]{5}{*}{ Scientic Concept } & $\mathrm{SC} 1$ & Defining of Sci. Correctly & 2 & 2 & 4 \\
\hline & $\mathrm{SCla}$ & Def. according to 2 attibute & 0 & 0 & 0 \\
\hline & $\mathrm{SC} 2$ & Def. SC. Concept incorrectly & 1 & 1 & 1 \\
\hline & $\mathrm{SC} 3$ & Elaborate SC. Concept Correctly & 6 & 3 & 7 \\
\hline & $\mathrm{SC} 4$ & Elaborate SC. Concept Incorrectly & 2 & 0 & 1 \\
\hline \multirow[t]{2}{*}{ Everyday Concept } & DE1 & Define Everyday Concept Correctly & 3 & 6 & 10 \\
\hline & DE2 & Define Everyday Concept Incorrectly & 2 & 1 & 0 \\
\hline \multirow[t]{2}{*}{ misconceptions } & DM1 & Detected Misconception & 0 & 0 & 1 \\
\hline & DM2 & Undetected Misconception & 1 & 2 & 1 \\
\hline \multirow[t]{2}{*}{ feedback } & FE1 & Feedback Elaborated & 2 & 4 & 6 \\
\hline & FE2 & Feedback Not Elaborated & 8 & 9 & 9 \\
\hline Management Talk & MT & Management Talk Occurences & 39 & 33 & 26 \\
\hline \multirow[t]{6}{*}{ Questions } & Q1 & Open Questions: How, Why & 0 & 0 & 0 \\
\hline & Q2 & Closed Questions: What, Guesses & 22 & 22 & 18 \\
\hline & Q3 & Closed/Fill in the Missing Words & 0 & 1 & 0 \\
\hline & Q4 & Closed Why, How & 0 & 0 & 0 \\
\hline & Q5 & Closed Management & 10 & 16 & 17 \\
\hline & & Percentage & $100 \%$ & $100 \%$ & $100 \%$ \\
\hline
\end{tabular}

\subsection{Scientific Concepts}

In view of the fact that science has its own language, which differs in significant ways from the everyday language spoken (in their mother tongue) by both teachers and learners in their home or social surroundings, it remains a challenge for teachers to teach scientific concepts and new knowledge in a language different from the mother tongue language or in a type of "academic" language that is distinct from the everyday, common notion of scientific knowledge which is acquired in spontaneous, everyday situations. During science lessons, the teachers often struggle to introduce and/or convey scientific ways of interpreting and explaining scientific phenomena to the learners phenomena which they already talk about and know about in their own everyday experience and actions.

Table 1 reveals that high percentage of the teachers' defining of concepts was used to define everyday concepts as opposed to defining scientific concepts definition. In addition, the incorrect use of scientific concepts was apparent from all the classroom observations. The teaching approach employed by the teachers emphasised mainly empirical knowledge. In light of this instructional approach, it may be surmised that this approach may have negative developmental consequences for the learners' ability to internalise scientific concepts as anticipated and expected by the curriculum.

Furthermore, it was found in each case study that the teachers were presenting scientific concepts in isolation and failing to relate these scientific ideas and concepts both to each other and to the learners' everyday lives and experiential observations. Whatever the learners' ages, the use of English as a second language and the abstract nature of the terms, the meaning of the concepts were never clarified or rephrased to render them meaningful to the learners. All three of the teachers treated science as comprising mere facts to be memorised by the learners, without emphasising the meaning or processes linked to or signified by those concepts. In addition, the meaning of the terms was not clarified at a level that Grade 5 learners would understand, with no attempt being made by the teachers to relate the ideas and concepts to each other and/or to a process. It may be argued that Natural Science concepts are complex in nature and, therefore, compared to the concepts in other subjects, they require more explanation, meaningful interaction with the learners (other than the repetition of previous lessons or the learners being required to give one-word answers to closed-ended questions) and visual demonstrations. Furthermore, it appeared as if the 
teachers' explanations and definitions of concepts were taken primarily from the textbooks, while they seemed to structure the discussions in such a way that the focus was on obtaining the correct answer rather than on understanding and applying the relevant scientific principles. In addition, in cases in which the teachers did define and explain the concepts without relying on the textbook, these definitions and explanations were often not scientifically correct and were in fact very confusing. The textbooks used by the teachers and learners who participated in this study were generic and did not draw on the everyday knowledge of the learners in question. In other words, they were not culturally and/or contextually embedded in a way that would link the learners' everyday knowledge with the scientific terms being taught. Thus, both the textbooks and the way in which the teachers used them were extremely inadequate in terms of developing the learners' scientific knowledge.

\subsection{The Use of Everyday Concepts}

It is clear from Table 1 that the language used by the teachers was littered with everyday rather than 'academic' scientific concepts. In the majority of their lessons, the focus appeared to be on revision/repetition of a topic which had been taught previously, rather than on the development of new concepts or ideas. In other words, the teachers seemed to be focusing primarily on what the learners already knew, as was illustrated by the exclusive focus on asking closed questions to which it was obvious the learners already knew the answers. In each case the teacher failed either to establish whether deeper understanding had resulted from the lesson or to offer learning opportunities that were different from, or expanded upon, the learners' spontaneous, everyday forms of learning. Thus, the teaching of concepts was located mainly in everyday forms of learning. While there were, however, some instances of the teachers linking the scientific and the everyday, given the dearth of scientific concepts conveyed, it was not possible to claim with any certainty that the everyday concepts had been rendered scientific in any conscious or thought-out way. For this reason, it is worth arguing the that the science teaching, as a way of thinking, was not effective as the teachers were not linking scientific concepts in any meaningful or developmental way to what the learners had already experienced in their everyday lives and in such a way that would enable them to internalise and apply these scientific concepts.

\subsection{Types of Questions Used}

Table 1 provides evidence of the predominance of closed-ended questions accounted for closed management questions as compared to open-ended questions. In other words, questions beginning with "What" and management questions such as "Do you all understand?", predominated. In addition, it appeared that the 'what' questions were based primarily on revision of what had been taught in the previous lessons and also possibly on what the learners already knew from their everyday lives.

Thus these questions were posed merely in order to elicit one-word answers and without any kind of elaboration on the teachers' part. Neither were the learners invited to elaborate on their answers in order to demonstrate that they had understood the question posed both conceptually and cognitively. The tendency of learners to answer a lower order question in chorus was evident in all the teachers' lesson. This despite the fact that it should have been clear that choral responses do not indicate whether all the learners have understood the concept fully, or assimilated it at a cognitive level. Thus, the teachers missed the opportunity to ask questions that would encourage the learners to apply the new concepts to real-world phenomena. In addition, they failed to pose questions that required the learners to link the scientific concepts meaningfully to what they knew and had observed in their everyday world. Instead, the questions focused in a superficial way on what the learners knew or had seen in their everyday world but without meaningfully linking this knowledge to scientific knowledge.

\subsection{Teachers' Feedback to the Learners' Responses}

Table 1 illustrates that a small percentage of what the teachers had to say was used elaboratively in feedback. The teachers provided very little feedback to the learners during the course of the lessons and neither did they correct misconceptions. Their feedback comprised mostly repetition, reformulation or an acknowledgment of the learners' responses with the phrase "very good". Otherwise the teachers would ask additional lower order questions, thus giving the impression that the learners' answers were 'correct' but without necessarily showing any in-depth understanding. Even when the learners provided correct answers to the questions, the teachers did not bother to check whether they had actually understood the principles or ask the learners to elaborate on and clarify their responses.

\subsection{Dealing with Learners' Misconceptions}

Even when there were obviously misconceptions on the part of the learners or they were confused about the vocabulary used, the teachers tended not to answer the questions asked nor did they provide clarification in terms of 
language (the second language of all of the learners), instead the teachers would abandon the issue without further clarification and proceed to ask more questions that the learners would be able to answer 'correctly'.

Incorrect answers were not discussed by the teachers during the lesson nor were they used to develop the learners' understanding. Instead, they were simply ignored with no further comment or deeper explanation. In addition, the teachers did not point out the learners' mistakes by providing some kind of feedback in the form of a discussion with either the learner concerned or the entire class if the misconception appeared to be common. Thus, one could say that the teachers failed to identify their learners' misconceptions or to use such misconceptions to deepen the learners' conceptual understanding. Moreover, the teachers failed to offer their learners sound pedagogic explanations that would have helped them to transform their limited or erroneous ideas during the course of their learning. I would argue that this approach may even create more misconceptions among the learners as they will now progress further in their understanding and level of accuracy if misconceptions are not questioned by the teachers and clarified by further discussion in the class, with all learners being invited to participate and contribute to the discussion.

\subsection{Proportions of Teachers' Instructional Talk}

Sound pedagogical practice would lead one to expect the teacher would use much of her/his instructional time to focus on explaining, discussing and modelling new terms with the learners. However, as emerged from the findings of this study, the teachers did not utilise much of their teaching time for teaching concepts; instead, the majority of the time was taken up in managing the lessons. Even when they were introducing new concepts, the teachers tended to spend less time on the elaboration of the scientific phenomena in question and more on managing classroom behaviours and asking predominantly closed ended questions that were not designed to explore the learners' ideas (see Table 1, p. 6). Thus, the teachers failed to offer learners opportunities to understand and internalise scientific concepts. The main reason for this appeared to be the fact that they devoted minimal time to explaining, defining and discussing concepts with the learners. It is therefore safe to claim that the quality of the instructional talk during the teaching process in in all the lessons observed was insufficient to promote the learners' cognitive development as regards the understanding and assimilation of scientific concepts. This is highly problematic as the learners are supposed to be taught and helped to understand new scientific concepts in new ways and not to be questioned on what they already know.

\subsection{Findings from Interview Data}

The teachers' beliefs about how children learn have a major impact on the teachers' instructional practices. It was thus deemed critical to examine how their beliefs influenced the way in which they taught scientific concepts to their learners. Six themes, namely, scientific concepts, everyday concepts, types of questions, feedback to the learners' responses, addressing misconceptions and their own personal beliefs on how science should be taught in primary schools, were identified and were used in the analysis of the interview data.

\subsection{Scientific Concepts}

In their responses to the questions posed during the interviews, the teachers mentioned the significance of supporting the learning of science by using concrete materials, drawing from everyday examples, addressing the learners' misconceptions, and using questions that fostered critical thinking in science as core principles of teaching. It was, however, evident from the teachers' responses that they preferred to use the CAPS textbook as they regarded this as an easy alternative. In addition, the 'word bank' in the textbook was useful in guiding them in defining scientific concepts. Thus, they regarded the textbook as a major source of scientific knowledge and relied heavily on it to teach science content.

On the other hand, it appeared that the teachers in the study were not aware of the notion of bringing to the fore the relationships between concepts in the teaching of science, as not one of them mentioned this issue in their responses. It may be concluded that this was the primary reason for their failing to reveal the connection between scientific concepts in their instructional practices.

Below are some of statements made by the participants:

"Usually, with the CAPS textbooks, it is a bit easy because they have what they call a 'word bank' in their books. So, now, you don't necessarily need to have visual aids because you can use those meanings of the words.".

"It is much difficult to teach science, because there are no recourses in our school, and then now I have to refer to the text book only. I try to have pictures in the classroom, like charts so that at least there are some referrals".

While all three of the teachers referred to possible different methods of teaching scientific concepts, such as using visual aids and/or concrete materials, some of the teaching strategies to which they referred were not evident during 
the observation of their lessons and clearly did not form part of the observation framework. This may warrant further investigation by researchers in the field.

Below are statements from some of the participants:

"I use concrete materials for learners to see what I am teaching. They don't only theorise what I am teaching them, but they also visualise what I am teaching them so that they can gain more knowledge of about the concepts."

\subsection{Everyday Concepts}

Although the teachers appeared to be mindful of the need to incorporate and integrate everyday examples into their teaching, it appeared that they either did not know or did not understand the theoretical basis of this practice and thus, their interview responses did not convince the interviewer that they understood the critical 'why' of linking everyday knowledge with new scientific knowledge during the course of teaching and learning. This was confirmed by their teaching practices where they failed to use everyday examples successfully in ways that supported their learners' conceptual development.

The study found numerous inconsistencies between teachers' responses during the interviews and the observation of their actual classroom practices.

Below are statements made by the participants:

"I always use everyday concept to link them with the scientific concepts, I feel it is the easy way to relate to new concepts, through that way it brings about the knowledge of what they have already know and what they see in their daily living."

"I use learners' everyday examples, it is important to incorporate things that learners have experiences before or what they see and what they know in teaching and learning."

\subsection{Types of Questions}

Although the teachers appeared to be aware of the various types of question that should be used during science teaching and learning to promote logical reasoning and problem-solving skills in learners, this was rarely evident in the lessons which were observed. The study found that the teachers tended to use questions beginning with "What", and management questions such as "Do you all understand?".

Below are certain statements made by the participants:

"I use the WHY and the WHAT do you think questions. These types of questions are very important in their learning, because even if learners are given high order task, they will know how to justify the point of view."

"I use questions like what and how. The how questions will make the learners to think wisely, like how you think will happen."

\subsection{Dealing with Misconceptions}

The teachers in the study highlighted the importance of addressing learners' misconceptions and claimed that they made sure that the learners' misconceptions were addressed as soon as they became evident. However, in practice it appeared that their actual classroom teaching contradicted what they claimed. It was evident from the classroom observations that any misconceptions on the part of the learners that emerged during the lessons were not addressed and there was no further comment or deeper explanations. Thus, there was clearly an inconsistency between what the teachers said and their teaching practices.

The participants had the following to say:

"I first try to find out the knowledge they have, but if what they know is not correct, then my role is to give them the explanation with the correct examples."

"Me as an educator firstly is to teach them the correct way by giving them the correct explanation of the misconceptions they have."

\subsection{Teachers' Beliefs}

The teachers in the study articulated their personal beliefs about science teaching and learning and claimed that these beliefs shaped the way in which they structured their instructional practices. However, in practice, their actual classroom teaching appeared to be contrary to their purported beliefs. There were several inconsistencies between the teachers' responses during the interviews and the observations of their actual classroom practices. In many cases 
there was no link between a teacher's perceptions and beliefs and his/her practice. Some of the teaching strategies to which they referred as effective and appropriate to science teaching were rarely seen during the observation of their lessons and therefore did not form part of the observation framework.

\section{Discussion}

The way in which the teachers in the study appeared to orchestrate their instructional talk did not support well-known and accepted research on the conceptual development of primary school learners. The data revealed few instances of the teachers explaining scientific concepts in line with what constitutes or should form part of the teaching of scientific concepts. It was evident in Table 1 (p. 6) that every day, rather than 'academic' scientific concepts, dominated the teacher talk. In the majority of their lessons the focus appeared to be on revision/repetition of a topic which had been taught previously rather than on the development of the new concepts or ideas. The teachers' approach appeared to focus primarily on what the learners already knew, as was illustrated by the exclusive tendency to ask closed questions to which it was obvious the learners already knew the answer. In each case the teacher failed to establish whether deeper understanding had taken place or to offer learning opportunities that were different from, or expanded on, the learners' spontaneous, everyday forms of learning. While there were some instances of the teachers linking the scientific and the everyday, given the dearth of scientific concepts conveyed, it is not possible to claim with any certainty that the everyday concepts were rendered scientific in any conscious or thought-out way. For this reason, I would argue that science teaching as a way of thinking was not effective as the teachers did not link the scientific concepts in any meaningful or developmental way with what the learners had already experienced in their everyday live. The study observed that teachers were more concerned with teaching the learners the 'correct' (verbatim from the textbook) definitions of concepts without emphasising the meaning of these scientific concepts in terms of relationships and processes. There appeared to be very little teaching taking place that, in line with the constructivist approach advocated by the curriculum, was fostering any meaning making and knowledge construction of the scientific concepts and procedures. In other words, the learners were not being provided with relevant scientific procedures and rules to prepare them to solve scientific problems that they may encounter, as advocated in the CAPS. The findings of the study reinforce the findings of the study conducted by Muthivhi and Broom (2008) in a South African primary school where they observed that the Social Studies teachers relied only on the textbook for the teaching of science without clarifying abstract terms to the learners. In the Muthivhi and Broom (2008) study, as in this study, scientific concepts were presented in isolation without taking into account the meaning of the concepts while the relationships between the concepts were never addressed or developed. In light of this type of instructional practice, Muthivhi and Broom (2008) encouraged educators to revisit their teaching approaches in order to ensure meaningful learning. In their view, "instead of presenting content as unrelated factual material that only needs to be assimilated into pupils' memory, the teacher could have problematized the content and engaged his pupils in activities that foster meaningful".

Thus, the pedagogical practices observed in both schools did not contribute to or clarify the learners' understanding of the scientific concepts involved in understanding the processes and concepts through engaging them in learning activities that included, and were based on, their existing and spontaneously acquired science knowledge. Instead, the approaches of all three of the teachers in the study were focused on transmitting everyday knowledge to the learners without linking this knowledge in any meaningful ways to the relevant scientific concepts. This type of pedagogical practice does not have the potential to change learners' spontaneous forms of learning into formal scientific knowledge, particularly at the Grade 5 level. Accordingly, this form of pedagogical approach has been severely criticised by scholars in the field, and is not considered to mediate meaningful learning. With regard to this teaching approach, Muthivhi and Broom (2008) suggest that teachers link scientific concepts with the learners' everyday knowledge and experience so as to build on this knowledge and experience and thus foster the learners' scientific understanding, and then proceed to develop this understanding into a more 'academic' scientific understanding/knowledge. This approach enables learners to acquire the theoretical concepts and methods that have the potential to change their existing, everyday forms of learning and ultimately will help them to understand and explore their world in a more scientific way. In this context Fleer (2009) warned that when learning is located primarily or solely in children's everyday experience, without taking into account the matching of scientific concepts with this learning, then learning is merely connected to events that learners have already experienced in their everyday lives. She thus encourages educators to be more attentive to ways of teaching that focus on the development of scientific knowledge on the basis of the children's everyday experiences.

All three of the teachers in this study treated science as mere facts to be memorised by the learners without emphasising the meaning or processes attached to or signified by these concepts. No attempt was made by the 
teachers to relate ideas and concepts to each other and/or to a process. Instead, the teachers used textbooks as the main source of knowledge in their teaching of science. As already mentioned, in their study conducted in a South African primary school, Muthivhi and Broom (2008) observed that the Social Studies teachers presented scientific concepts in isolation and without taking into account the meanings of the concepts. Based on my own teaching experience, I would argue that the textbooks used by the teachers and learners in this study were generic and did not draw on the everyday knowledge of the specific learners.

\section{Conclusions}

The study collected data on the way in which scientific concepts were being taught by a sample of three teachers to learners at three schools in a particular socioeconomic context. Based on the overall findings it may be argued that the empirical teaching approaches which manifested in the three case studies explored in this research are not only at odds with the existing research on and knowledge of the cognitive conceptual development of learners at the Grade 5 level, but also the teaching and learning theories of Vygotsky (1978). It was clear from the study that the three teachers had no theoretical understanding of the way in which science concepts should be taught to their learners in a way that took into account their cognitive and conceptual development at this grade level. The data from the study suggest that there is little doubt that the serious shortcomings evident in the teachers' instructional practices are not confined to these three schools but are probably present in township primary schools in general. This highlights the need for immediate interventions on the part of senior curriculum specialists as well as teacher training higher education institutions (HEIs). The use of an empirical approach to the development of scientific concepts in the Natural Science lessons observed did not appear to foster fruitful learning and sustainable conceptual development in learners in these lessons. The teachers' lack of knowledge regarding scientific content as well as their personal beliefs in respect of the way in which science should be taught to primary school learners were clearly inhibiting them from facilitating effective and meaningful conceptual learning in their classrooms. I would argue that the relatively small percentages of teacher talk and lesson time devoted to concept teaching, the teachers' lack of awareness of (ignorance of) and their failure to address learner misconceptions, and the use of a single textbook had a direct impact on the learners' conceptual development and played a leading role in the learners' poor academic performance in science. While the findings of the study applied to three specific teachers only, it is hoped that the findings of this study will resonate with primary school teachers in similar situations to find a resonance with their own instructional practices and lead them to consider how the conceptual development of learners in science could or should be taken into account in their own teaching practice.

\section{Limitations of the Study}

There are several limitations to this study, including the fact that the findings from the case study are not generalisable owing to the small number of participants involved. However, the findings could be further developed through research that focuses on a broader sample of participants.

\section{Recommendations}

The following recommendations are made based on the findings of this study:

Teacher training should focus on programmes that are theoretically oriented, such as those informed by Vygostky's theory, in particular, his notion of conceptual development, and that emphasise both cognitive development in learning and conceptual teaching which results in the learners developing accurate, comprehensive and mature concepts as well as reflective problem-solving and decision-making skills and practices.

\section{Acknowledgements}

We thank all the respondents who took the time to take part in the interviews conducted for the purposes of the study. Without their participation this study would not have been a success or even possible. We would also like to thank the Department of Education for having granted us permission to conduct the research at three of its schools.

\section{Competing interests}

The researchers declare that they had no financial or personal relationship(s) which may have inappropriately influenced them in the writing of this article. 


\section{References}

Askew, M. (2013). Mediating learning number bonds through a Vygotskian lens of scientific concepts. South African Journal of Childhood Education, 3(2), 1-20. https://doi.org/10.4102/sajce.v3i2.37

Baxter, P., \& Jack, S. (2008). Qualitative case study methodology: Study design and implementation for novice researchers. The Qualitative Report, 13(4), 544-559.

Burgess, R. G. (1989). The ethics of educational research. Journal of Philosophy of Education, 40(2), 131-135. https://doi.org/10.2307/3121426

Creswell, J. (2007). Qualitative inquiry \& research design: Choosing among five approaches. Journal of Autism and Developmental Disorders, 38(3), 581-591.

Creswell, J. W. (2005). Educational research: Planning, conducting, and evaluating quantitative and qualitative research (2nd ed.). Upper Saddle River, NJ: Merrill.

Department of Basic Education (DBE). (2011). National Curriculum Statement (NCS). Curriculum and Assessment Policy Statement: Mathematics, Senior Phase Grades 7-9. Cape Town: Department of Education.

Department of Education (DoE). (2005). Grade 6 National Systemic Evaluation Report. Pretoria: Department of Education.

Fleer, M. (2008). Understanding the dialectical relations between everyday concepts and scientific concepts within play-based programs. Research in Science Education, 39, 281-306.

Department of Education (DOE). (2008, 14 March). Foundations for Learning Campaign. Pretoria: Department of Education.

Fleer, M. (2009). Supporting scientific conceptual consciousness or learning in a 'roundabout way' in play-based contexts. International Journal of Science Education, 31(8), 1069-1089. https://doi.org/10.1080/09500690801953161

Fleisch, B. (2008). Primary education in crisis: Why South African schoolchildren under achieve in reading and mathematics. Cape Town, South Africa: Juta.

Gomez-Zwiep, S. (2008). Elementary teachers' understanding of students' science misconceptions: Implications for practice and teacher education. Journal of Science Teacher Education, 19(5), 437-454. https://doi.org/10.1007/s10972-008-9102-y

Hardman, J. (2005). Activity theory as a framework for understanding teachers' perceptions of computer usage at primary school level in South Africa. South African Journal of Education, 25(4), 258-265.

Lather, P. (1986). Issues of validity in openly ideological research: Between a rock and a soft place. Interchange, 17(4), 63-84. https://doi.org/10.1007/BF03219544

Lather, P. (1991). Getting smart: Feminist research and pedagogy with/in the postmodern. Fetter Lane, London: Routledge.

Maxwell, J. (2005). Qualitative research designs an interactive approach. Thousand Oaks, CA: Sage Publications.

Mercer, N. (2010). The analysis of classroom talk: Methods and methodologies. British Journal of Educational Psychology, 80(1), 1-14. https://doi.org/10.1348/000709909X479853

Muthivhi, A. E. (2008b). Language policy, classroom practice and concept learning in a Grade 1 Tshivenda classroom. Southern African Review of Education, 14(3), 23-35.

Muthivhi, A., \& Broom, Y. (2008). Continuities across schooling transition: A case of classroom practices among teachers in Venda, South Africa. Journal of Educational Studies Volume, 7(1), 98-121.

Probyn, M. (2005). Language and the struggle to learn: The intersection of classroom realities, language policy, and neo-colonial and globalisation discourses in South African schools. In A. Lin, \& P. Martin (Eds), Decolonisation, globalisation language-in-education policy and practice. Clevedon, OH: Multilingual Matters.

Ritchie, Jane, Lewis, Jane \& Elam, Gillian. (2003). Designing and selecting samples. In Jane Ritchie \& Jane Lewis (Eds.), Qualitative research practice: A guide for social science students and researchers (pp.77-108).

Schollar, E. (2008). Final report: The Primary Mathematics Research Project 2004-2007. Towards evideence-based educational development in South Africa. Johannesburg: Eric Schollar\& Associates. 
Setati, M., Adler, J., Reed, Y., \& Bapoo, A. (2002) Incomplete journeys: Code-switching and other language practices in mathematics, science and English language classrooms in South Africa. Language and Education, 16(2), 128-149. https://doi.org/10.1080/09500780208666824

Taylor, N. (2008). What is wrong with South African schools? Retrieved from JET Education Services: www.jet.org.za

Thousand Oaks, CA: SageRivalland, C. (2007). When are beliefs just 'the tip of the iceberg'? Exploring early childhood professionals' beliefs and practices about teaching and learning. Australian Journal of Early Childhood, 32(10), 30-37. https://doi.org/10.1179/146431510X12626982043840

Tomita, M. K. (2008). Examining the influence of formative assessment on conceptual accumulation and conceptual change (Doctoral dissertation). Stanford University. 